\title{
A COMPETÊNCIA PENAL NOS CYBERCRIMES
}

Lucas de Oliveira Ramos, Christian Santos Oliveira, Bruno Ribeiro dos Santos, Eduardo Buzetti Eustachio Bezerro.

Universidade do Oeste Paulista - UNOESTE, curso de Direito, Presidente Prudente, SP. E-mail: eduardobuzetti@hotmail.com

\section{RESUMO}

O presente artigo tem como objetivo demonstrar a contextualização do desenvolvimento da internet, seu expansionismo, e o alcance da popularização e a inevitável prática criminosa por meio do ambiente virtual. Nesse passo, após desenvolver noções gerais acerca do uso da internet e sua finalidade precípua, passou-se a analisar a prática de infrações penais por meio dos cybercrimes, bem como, desenvolver quais as regras aplicáveis para a definição da competência penal para a investigação, processo e julgamento de infrações penais praticadas pelo ambiente virtual.

PALAVRAS-CHAVE: Cybercrimes. Direito penal. Competência penal. Internet. Intervenção.

\section{THE CRIMINAL JURISDICTION IN CYBERCRIMES}

\section{ABSTRACT}

The present article aims to demonstrate the contextualization of the development of the internet, its expansionism, and the reach of popularization and the inevitable criminal practice through the virtual environment. In this step, after developing general notions about the use of the Internet and its main purpose, we began to analyze the practice of criminal offenses through cybercrimes, as well as to develop the rules applicable to the definition of criminal jurisdiction for investigation, process and judgment of criminal infractions practiced by the virtual environment.

KEYWORDS: Cybercrimes. Criminal law. Criminal jurisdiction. Internet. Intervention.

\section{INTRODUÇÃO}

Ao pensar em crimes informáticos devemos primeiramente pensar em o que é crime, sendo assim, crime é todo fato típico, antijurídico, e culpável, onde acontece uma ação ou omissão ilícita, que a lei impõe uma sanção de natureza penal. Dito isso passamos a falar sobre o tema em inteiro.

Com a crescente evolução tecnológica no mundo, muitas coisas que eram executadas manualmente deixaram de ser, na maioria das vezes as pessoas utilizam equipamentos eletrônicos conectados a internet para desenvolver alguma atividade, são imensas as possibilidades na tão famosa internet, novas relações sociais passaram a fazer parte dessa era digital, e essa é uma das razões pelo qual o Direito deve se moldar a essa nova realidade em que estamos vivendo, caminhar em conjunto com a segurança, para que essa sociedade digital não se torne um caos.

Com o uso da internet cada vez maior, os crimes já tipificados pelo Código Penal passaram a ser praticados também através do meio virtual, assim como, surgiram novas modalidades de crimes os denominados crimes cibernéticos, que infelizmente apesar de fazerem parte da realidade brasileira, carecem de uma legislação especifica para a punição dos responsáveis pelo 
delito, pois não existe uma fronteira entre os usuários que se relacionam na internet através de uma rede interligada.

O trabalho desenvolvido foi objeto de uma pesquisa frente aos principais autores que discorrem sobre a relação do Direito Penal com os crimes que ocorrem em ambiente virtual, utilizando na pesquisa o método dedutivo, pois foi feita uma pesquisa bibliográfica a partir de livros, artigos, e sites na internet que já versavam sobre o assunto.

\section{METODOLOGIA}

O presente artigo será feito pelo modo de pesquisa explicativa, através de raciocínio hipotético dedutivo, com o uso bibliográfico tanto em livros físicos quanto em mídias online, onde acontecerá uma analise e criticas construtivas sobre o tema pesquisado, tem um contexto social e dialético com o uso de dados de pesquisadores e doutrinadores que escrevem sobre o tema do projeto.

\section{DESENVOLVIMENTO}

Ao pensar em crimes Informáticos devemos primeiramente pensar em o que é crime, sendo assim crime é todo fato típico, antijurídico, e culpável, onde acontece uma ação ou omissão ilícita, que a lei impõe uma sanção de natureza penal. Dito isso passamos a falar sobre o tema em inteiro.

De acordo com (NERY, BITTENCOURT, AZAMBUJA, 2013, p. 1) “A Internet é rica, e onde há riqueza, existe crime.", vemos que o entendido por Nery é algo que a maioria da sociedade entende igualmente, pois esse entendimento é algo que vem de muito tempo com a nossa cultura onde as nossas maiores riquezas foram praticamente extintas usando de um crime.

Para Nicholas Carr (apud GERSCHENFELD, 2010, p. 2) "A Internet está mudando a nossa forma de pensar.", esse é um pensamento grandioso e certeiro, pois com os últimos acontecimentos presentes pertinentes ao tema do trabalho conseguimos observar que além dos crimes estarem mudando o pensamento da sociedade muda também.

Um dos fundadores da internet, Tim Berners-Lee (junho, 2006), contrariando o que muitos imaginariam, chegou a firmar que "foi sugerido que não necessitamos de legislação sobre a internet, pois até hoje não temos legislação e ela não teria feito falta”. E continua: “... é bobagem, porque tínhamos liberdade no passado, mas a ameaça explicita e reais a esta liberdade surgiram apenas recentemente".

Como podemos observar Tim Berners não imaginava que a internet ficaria intensa e grande como esta hoje, necessitando assim de uma legislação sobre ela, pois o nosso Código Penal foi elaborado diante de uma realidade majoritariamente física, os bens protegidos, em boa parte, são bens tangíveis, matéria. Os raciocínios foram criados diante da criminalidade possível á época, conforme a sociedade modificou - se reformas e novidades legislativas devem surgir como modo de abranger novas áreas a se proteger.

Com a inovação vieram os crimes, foi em 1839 quando Alan Turing foi recrutado pelo Serviço de Inteligência Americana para descobrir o segredo das maquinas codificadoras eletromagnéticas, assim sendo estudadas as técnicas e códigos para se ocultar ou proteger a informação.

O doutrinador JESUS, Damásio, 2015, p. 22 diz que "A doutrina diverge acerca do primeiro delito informático cometido. Para alguns, o primeiro delito informático teria ocorrido no âmbito do MIT (MassachussettsInstituteof Technology), no ano de 1964, onde um aluno de 18 anos teria cometido um ato classificado com cybercrimes, tendo sido advertido pelos superiores".

Colloquium Socialis, Presidente Prudente, v. 01, n. Especial 2, Jul/Dez, 2017, p.45-49. DOI: 10.5747/cs.2017.v01.nesp2.s0114 
Assim, conceituamos crime informático como o fato típico e antijurídico come- tido por meio da ou contra a tecnologia da informação. Decorre, pois, do Direito informático, que é o conjunto de princípios, normas e entendimentos jurídicos oriundos da atividade informática. Assim, é um ato típico e antijurídico, cometido através da informática em geral, ou contra um sistema, dispositivo informático ou rede de computadores. Em verdade, pode-se afirmar que, no crime informático, a informática ou é o bem ofendido ou o meio para a ofensa a bens já protegidos pelo Direito Penal.

Marco Aurélio Rodrigues da Costa, por sua vez, em conceituação mais especifica, aponta que crime de informática é todo aquele procedimento que, utilizando-se de um sistema de processamento de dados, atenta contra os dados que estejam armazenados, compilados, sejam transmissíveis ou em transmissão.

Deste modo, o que se tem é que os crimes informáticos podem ser amplamente compreendidos, dividindo-se em: a) meio tecnológico como alvo da conduta; b) meio eletrônico como ferramenta para conseguir obter a finalidade delituosa.

A questão da territorialidade encontra guarida no Código Penal e de Processo Penal brasileiros, embora seja tema considerado de relativa controvérsia.

O doutrinador (JESUS, Damásio de. Manual de crimes informáticos, 1a edição.. Saraiva, 12/2015) diz que:

No que tange ao lugar do crime, o Código Penal adotou, em seu art. $6^{\circ}$, a teoria da ubiqüidade, sendo considerado o lugar do crime o local onde ocorreu a ação ou omissão, no todo ou em parte, bem como onde se produziu ou deveria se produzir o resultado. Deste modo, ao se considerar alguém, no Estado do rio de Janeiro, que invade o computador de outrem, localizado em são Paulo, teríamos o juízo onde está o dispositivo invadido como competente para processar e julgar o delito informático.

Já no que diz respeito a condutas ilícitas praticadas em território estrangeiro, não se aplicariam as normas brasileiras, considerando a soberania do país, sendo que a questão deverá ser tratada pela extradição.

Poderíamos, pensar aqui, na aplicação de algumas regras trazidas pelo CPP, em seus art. 70 e 88. Vejamos:

Art. 70 . A competência será, de regra, determinada pelo lugar em que se consumar a infração, ou, no caso de tentativa, pelo lugar em que for praticado o último ato de execução.

1ㅇ Se, iniciada a execução no território nacional, a infração se consumar fora dele, a competência será determinada pelo lugar em que tiver sido praticado, no Brasil, o último ato de execução.

2ㅇ Quando o último ato de execução for praticado fora do território nacional, será competente o juiz do lugar em que o crime, embora parcialmente, tenha produzido ou devia produzir seu resultado.

30 Quando incerto o limite territorial entre duas ou mais jurisdições, ou quando incerta a jurisdição por ter sido a infração consumada ou tentada nas divisas de duas ou mais jurisdições, a competência firmar-se-á pela prevenção.

Art. 88. No processo por crimes praticados fora do território brasileiro, será competente o juízo da Capital do Estado onde houver por último 
residido o acusado. Se este nunca tiver residido no Brasil, será competente o juízo da Capital da República.

De modo esclarecedor, Damásio Evangelista de Jesus (apud Valin, 2000, p. 117) entende que, para casos relacionados à internet, deveria ser adotado algo semelhante à teoria da atividade que, como visto, determina como sendo o local do crime aquele em que o agente praticou o delito.

Pensamento contrário é defendido por Valin (2000, p. 117), que acredita ser a melhor solução considerar-se como local do crime aquele em que está o autor das infrações, pois o referido país teria melhores condições de aplicar eventual pena, sem necessidade de discussão sobre extradição, no máximo se discutiria o cumprimento dos efeitos cíveis da condenação no sentido de retirar da rede o material publicado, o que talvez possa gerar a necessidade de um novo processo em país distinto ao da condenação".

Importa dizer ainda que, nos termos do $\S 2^{\circ}$ do art. 70 do código de Processo Penal, quando atos executórios tenham ocorrido fora do Brasil, a competência será do local onde a infração se deu ou foi concluída a ação delituosa (resultado).

Sobre o assunto o STJ diz que a competência será, de regra, determinada pelo lugar em que se consumar a infração.

Aparentemente simples a solução, mas, surgem alguns questionamentos neste momento. Ora, qual seria o tratamento no caso de sites hospedados em provedores localizados fora do Brasil? Estaríamos diante de hipótese de competência internacional? Concorrente ou exclusiva? Como o provedor hospedado no território de outro país, seria este Estado o competente para o processo e julgamento do crime? Estaria automaticamente excluída a competência da justiça brasileira neste caso? $\mathrm{O}$ autor deste crime, domiciliado no Brasil, seria processado e julgado pela Justiça estrangeira, do local em que hospedado o site?

Ainda não temos no cenário atual, de total omissão legislativa sobre os crimes desta natureza, respostas absolutas para estas perguntas. Parece-nos seguir o entendimento da premissa firmada pelo STJ na aplicação da legislação comum, com fundamento no sobredito art. 70 do Código de Processo Penal.

\section{CONCLUSÃO}

Após a realização deste artigo fica claro que o crime não é novidade no nosso ordenamento jurídico, e que os problemas que vieram a existir por meio da "internet" devem ser discutidos cada vez mais, pois estes crimes podem ocasionar grandes problemas para a sociedade.

A competência penal dos crimes cibernéticos é um assunto com muita controvérsia porém hoje já existe uma predominância, que entende que a competência será onde a infração se deu ou foi concluída, o que transparece a adoção pela aplicabilidade da teoria do resultado, admitindo a aplicabilidade da teoria da conduta ou atividade apenas aos crimes tentados.

\section{REFERÊNCIAS}

JESUS, Damásio de. Manual de crimes informáticos, 1.ed. São Paulo: Saraiva, 2015.

SYDOW, Spencer Toth. Coleção Saberes monográficos: Crimes informáticos e suas vítimas, 2.ed. São Paulo: Saraiva, 2014. 
BOBBIO Norberto ET AL. Dicionário de policia. 7.ed.Brasilia: 1995.

ALBUQUERQUE, Roberto Chacon de. A criminalidade informática. São Paulo, Saraiva, 2006.

NERY, Claudio Lima; BITTENCOURT, Manoela de; AZAMBUJA, Mariana Menna Barreto. A proteção de dados pessoais e a internet. Disponível em: http://www.tex.pro.br/home/artigos/258-artigosdez-2013/6364-a-protecao-de-dados-pessoais-e-a-internet-the-personal-data-protection-and-theinternet Acesso em 15 ago. 2017. 